\title{
Controle independente de fluxos em dispositivos microfluídicos
}

\section{Lucas C. Ferreira*, Varlei Rodrigues, Antonio Riul Jr.}

\section{Resumo}

Este projeto tem como objetivo confeccionar uma microbomba de seringa que possibilite o controle de fluxos distintos no interior de um microcanal, utilizando para desenvolvimento do projeto um controlador Arduino para realizar o controle de fluxos em um dispositivo microfluídico. Fizemos uso também da tecnologia de impressão 3D para construção das peças.

Palavras-chave: Layer-by-Layer, Automação, Impressão 3D

\section{Introdução}

A microfluídica [1-3] é uma linha de investigação científica crescente na última década e pode ser brevemente definida como o controle e estudo de fluídos em escala sub-milimétrica. Para isso é necessária a inserção de líquidos no interior de microcanais por pressão, capilaridade ou outras técnicas. O objetivo deste projeto é confeccionar microbombas de seringa utilizando impressão 3D para construção estrutural e o Arduino [4] para programá-las, de maneira a construir um sistema acoplado que controle a injeção de dois fluxos de maneira independente no interior de um microcanal. O aparato tornaria possível, por exemplo, analisar o crescimento de filmes ultrafinos ou verificar a passagem laminar de fluído em diferentes designs e aplicações.

\section{Resultados e Discussão}

O foco inicial do projeto foi projetar as peças e aprender a utilizar o Arduino. No que se refere à confecção das peças, foi utilizado o software CAD inventor [5], que permitiu construir um esboço 2D das mesmas e então utilizar um comando para de extrusão de material para fabricação dos objetos através do CAD em uma impressora 3D. Além disto, foi necessário aprender a plataforma de programação do Arduino uno, mais especificamente, a interação entre o Arduino e um motor de passo que seria utilizado para controlar o êmbolo da seringa e, desta maneira, inserir o líquido em um microcanal.

Como resultados preliminares, foi possível utilizar o software Inventor para projetar as peças e imprimi-las em uma impressora 3D (Figura 1), controlar o Arduino para acender LEDs e construir circuitos mais simples seguindo tutoriais, para depois montar um circuito que controla o motor de passo, movimentando-o de maneira simples no sentido horário ou anti-horário com velocidades controladas.

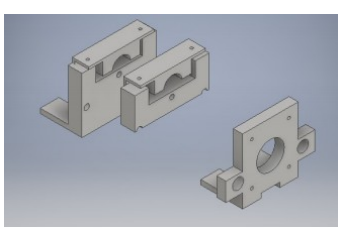

(a)

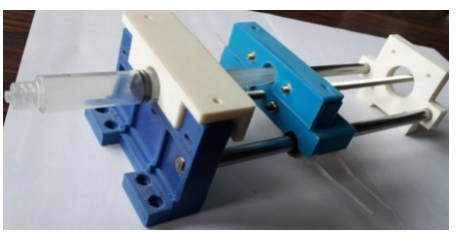

(b)
Figura 1. (a) Desenho esquemático da estrutura suporte para fabricação da microbomba. (b) peças confeccionadas na impressora 3D pelo aluno Filipe del Nero.

Entretanto, esta etapa foi apenas iniciada pois houve um cancelamento do projeto no segundo semestre de atividades.

\section{Conclusões}

No primeiro semestre de desenvolvimento focamos no aprendizado das técnicas para projetar as peças, incluindo aprendizado dos softwares envolvidos no projeto e também na impressão 3D das peças. Contudo, devido a carga didática ao longo do semestre optamos em interromper os desenvolvimentos de maneira a não prejudicar disciplinas na graduação.

\section{Agradecimentos}

Agradeço ao SAE e a CNPQ pelo financiamento do projeto e aos orientadores.

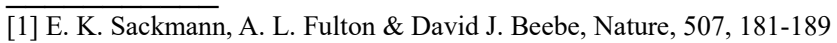
(2014)

[2] S.L.S. Freire, Sensors and Actuators A, 250, 15-28 (2016)

[3] H.A. Stone, A.D. Stroock, \& A. Ajdari, Annual Review of Fluids Mechanics, 36, 381-411 (2004)

[4] https://www.arduino.cc/en/Guide/HomePage, acesso em 28 de junho de 2017

[5] http://www.autodesk.com.br/products/inventor/overview, acesso em $28 \mathrm{de}$ fevereiro de 2017 